\title{
A Mars Environment Chamber Coupled with Multiple In Situ Spectral Sensors for Mars Exploration
}

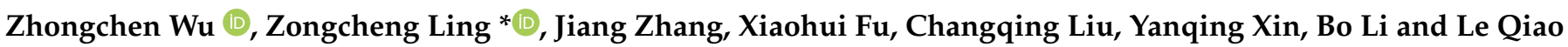 \\ Shandong Key Laboratory of Optical Astronomy and Solar-Terrestrial Environment, School of Space Science and \\ Physics, Institute of Space Sciences, Shandong University, Weihai 264209, China; z.c.wu@sdu.edu.cn (Z.W.); \\ zhang_jiang@sdu.edu.cn (J.Z.); fuxh@sdu.edu.cn (X.F.); liucq@mail.sdu.edu.cn (C.L.); yqxin@sdu.edu.cn (Y.X.); \\ libralibo@sdu.edu.cn (B.L.); leqiao@sdu.edu.cn (L.Q.) \\ * Correspondence: zcling@sdu.edu.cn
}

check for updates

Citation: Wu, Z.; Ling, Z.; Zhang, J.; Fu, X.; Liu, C.; Xin, Y.; Li, B.; Qiao, L. A Mars Environment Chamber Coupled with Multiple In Situ Spectral Sensors for Mars Exploration. Sensors 2021, 21, 2519. https:// doi.org/10.3390/s21072519

Academic Editor: Federico Angelini

Received: 9 February 2021

Accepted: 21 March 2021

Published: 4 April 2021

Publisher's Note: MDPI stays neutral with regard to jurisdictional claims in published maps and institutional affiliations.

Copyright: (c) 2021 by the authors. Licensee MDPI, Basel, Switzerland. This article is an open access article distributed under the terms and conditions of the Creative Commons Attribution (CC BY) license (https:// creativecommons.org/licenses/by/ $4.0 /)$.
Abstract: Laboratory simulation is the only feasible way to achieve Martian environmental conditions on Earth, establishing a key link between the laboratory and Mars exploration. The mineral phases of some Martian surface materials (especially hydrated minerals), as well as their spectral features, are closely related to environmental conditions. Therefore, Martian environment simulation is necessary for Martian mineral detection and analysis. A Mars environment chamber (MEC) coupled with multiple in situ spectral sensors (VIS (visible)-NIR (near-infrared) reflectance spectroscopy, Raman spectroscopy, laser-induced breakdown spectroscopy (LIBS), and UV-VIS emission spectroscopy) was developed at Shandong University at Weihai, China. This MEC is a comprehensive research platform for Martian environmental parameter simulation, regulation, and spectral data collection. Here, the structure, function and performance of the MEC and the coupled spectral sensors were systematically investigated. The spectral characteristics of some geological samples were recorded and the effect of environmental parameter variations (such as gas pressure and temperature) on the spectral features were also acquired by using the in situ spectral sensors under various simulated Martian conditions. $\mathrm{CO}_{2}$ glow discharge plasma was generated and its emission spectra were assigned. The MEC and its tested functional units worked well with good accuracy and repeatability. China is implementing its first Mars mission (Tianwen-1), which was launched on 23 July 2020 and successfully entered into a Mars orbit on 10 February 2021. Many preparatory works such as spectral databases and prediction model building are currently underway using MECs, which will help us build a solid foundation for real Martian spectral data analysis and interpretation.

Keywords: Mars simulation; Mars chamber; space instrumentation; Raman; LIBS; $\mathrm{CO}_{2}$ glow discharge

\section{Introduction}

The environmental conditions of the Martian surface, such as the atmospheric composition, gas pressure, temperature, humidity and UV radiation levels, differ sharply from Earth ambient conditions. The mineral phases of some Martian minerals and their spectral features are closely related to environmental conditions [1-3]. For example, some hydrated minerals will obtain or lose some degree of structural water, and the Raman peak of water also shifts or deforms according to the low temperature [1]. On the other hand, the environmental conditions also significantly impact certain measurement techniques. Laserinduced breakdown spectroscopy (LIBS) is a typical dynamic measuring technology whose spectral profile depends heavily on the gas species and gas pressure around the target $[4,5]$. Therefore, environmental simulation is critical for Martian mineral detection and analysis; it is also the only feasible way to mimic the conditions of the Red Planet in the laboratory and enable the interpretation of real Martian data. Accordingly, the ChemCam team and SuperCam team calibrated and recalibrated their LIBS prediction model before/during the mission under simulated Mars conditions [6-9]. In fact, due to their irreplaceable role, planetary simulation chambers have experienced major improvements in terms of 
methodological models and instrumental designs, enabling various simulated experiments related to Mars [10-13], the Moon [14,15] and asteroid/cometary/solar system small bodies $[15,16]$ for mineral analysis [10], astrobiology [11,17], instrument calibration/materials testing [6,9], planetary exploration [18] studies, and so on.

Currently, China is implementing its first Mars mission (Tianwen-1), which consists of three subtasks (one orbiter, one lander, and one rover), and this mission was launched (Wenchang Satellite Launch Center, China) on 23 July 2020. A total of 13 payloads were selected, seven of which were installed on the rover. A LIBS system, a passive VIS (visible)NIR (near-infrared) spectrometer, and a remote microimager (RMI) were combined to make one integrated system (MarsCoDe) for Martian surface material elemental and composition detection and analysis [19].

In this study, one Mars environment chamber (MEC) coupled with four types of in situ spectral sensors (ASD spectrometer (Analytical Spectral Devices Inc., the commercial field-portable full-range UV/Vis/NIR/SWIR spectrometers), fiber Raman spectrometer, LIBS system and UV-VIS plasma emission spectrometer) was built at Shandong University. Though this system has the ability to analyze homogeneous geological samples by hyphenated spectral methods, the main aim of this paper is to introduce the work function, performance of MEC, and every coupled spectral sensor at various environmental and work parameters. Different samples and various gas pressures were used to demonstrate the performances of Raman, LIBS, and glow discharge emission spectral units. The MEC can regulate Mars-relative environmental parameters (gas components, gas pressure, sample temperature/humidity, and UV radiation dosage) and simultaneously or sequentially execute multiple in situ spectral measurements. The spectral characteristics (VIS-NIR, Raman, and LIBS) of some geological samples can be obtained within a few seconds under given Martian environmental conditions. In this study, (1) the structure, function, and performance of MEC were systematically introduced; (2) the spectral features of some geological samples were recorded and analyzed by in situ spectral sensors under various simulated Martian conditions; (3) the $\mathrm{CO}_{2}$ glow discharge induced by Mars dust storms/devils were simulated in the MEC. In addition, the free radicals and the electrochemical reaction products were monitored in situ by emission spectrometry during $\mathrm{CO}_{2}$ glow discharge. This system establishes a pathway to link the experimental data from the laboratory to the real spectral data obtained from Mars missions.

\section{Mars Environment chamber}

\subsection{Chamber Structure}

As shown in Figure 1, the Mars chamber mainly consists of a customized stainless box-shaped vacuum chamber $(25 \times 25 \times 25$ inches, Kurt J. Lesker Company, Jefferson Hills, PA, USA). A dozen flange interfaces were designed and mounted on the walls of the chamber, which were fixed by electronic/optical feedthroughs for sample spectral data collection and chamber environmental parameter control, maintenance, and monitoring. Two circular quartz viewports were mounted on the right (diameter: $200 \mathrm{~mm}$ ) and top (diameter: $100 \mathrm{~mm}$ ) walls of the chamber for LIBS laser input, plasma signal transmission, and UV radiation. Rectangular glass observation widows (width: $150 \mathrm{~mm}$, height: $250 \mathrm{~mm}$ ) were installed in the middle of the front door. Five optical breadboards were fixed on the inside wall of the chamber (except for the front door) for accessory fixation and adjustment. 
A

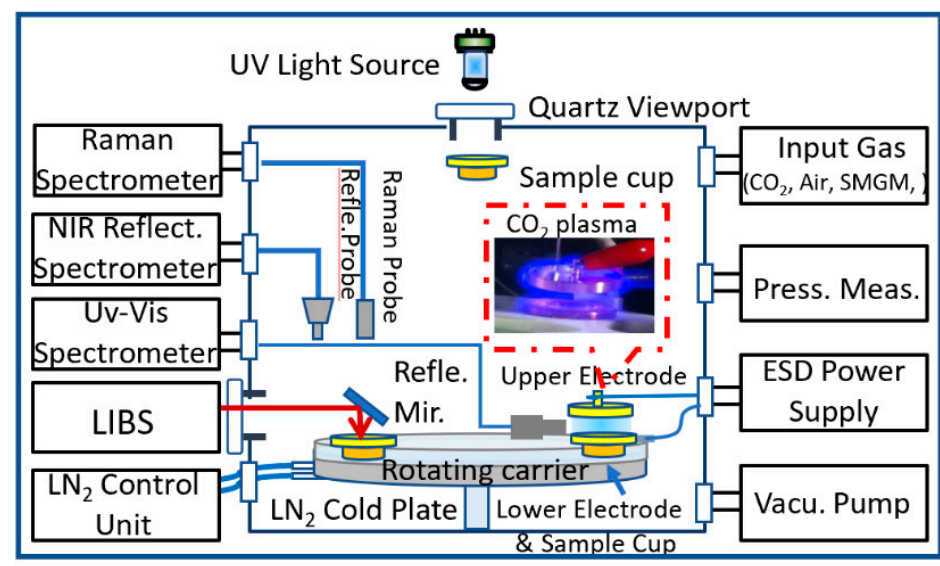

B

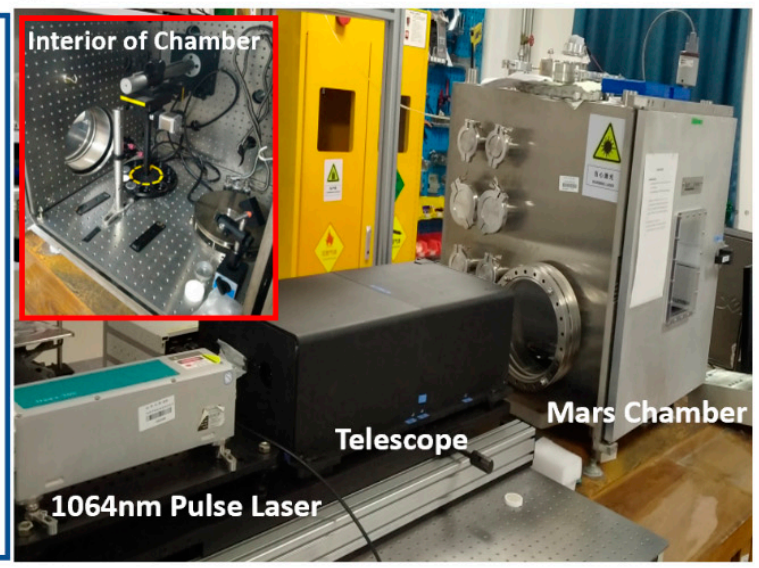

Figure 1. (A) Schematic diagram of the Mars chamber and peripheral function units. The inset is a photograph of $\mathrm{CO}_{2}$ plasma generated between two copper plate electrodes. (B) Photograph of the Mars chamber. The upright image is a photograph of the interior of the Mars chamber. The spectral sensor can be used for in situ detection of minerals in chambers or free radicals in $\mathrm{CO}_{2}$ plasma.

The MEC was designed to simulate the Martian gas pressure, surface temperatures, humidity, and UV radiation. Under these simulated conditions, multiple in situ spectroscopic measurements of geological samples can be performed well.

\subsection{Chamber Function}

\subsubsection{The Regulation of Gas Pressure and Components}

For accurate and reliable gas pressure control and measurement, a gas pressure controller (946 Vacuum System Controller, MKS Instruments, Andover, MA, USA), a pressure sensor (model: KJL300808, MKS Instruments, Andover, MA, USA), an electronic mass flow meter, and an oil-free vacuum pump (XDS35i, Edwards Ltd., Flintshire, UK) were used to dynamically control the gas pressure (from 0.1 to $1000 \mathrm{~Pa}$ ) inside the chamber. A gas cylinder was used to supply pure $\mathrm{CO}_{2}$ gas or commercial Martian simulated gas mixtures to the MEC as the working gas. A customized four-channel gas mixer was also used for in situ gas mixing $\left(\mathrm{CO}_{2}, \mathrm{~N}_{2}, \mathrm{Ar}\right.$, and $\left.\mathrm{O}_{2}\right)$ during pumping by using four electronic gas flowmeters (Flowmethod Co., Ltd., Shenzhen, China). The gas species and their relative amounts can be well regulated.

The gas pressure control system worked effectively, with relatively high accuracy and reproducibility $( \pm 2.0 \mathrm{~Pa}$ at $700 \mathrm{~Pa})$. The gas pressure of the chamber can be well controlled. As seen in Figure 2, the gas pressure inside the chamber continuously decreased to the set point after the gas pressure controller system began to work (pressure $<1100 \mathrm{~Pa}$ ). The minimum pressure (100 Pa) was achieved within $\sim 200 \mathrm{~s}$. Some gas pressure curves showed slight oscillations near the set point, for example, $700 \mathrm{~Pa}$ in this case. This is a normal phenomenon for gas control in vacuum systems [20].

\subsubsection{The Regulation of Temperature and Humidity}

In the chamber, only the temperature of the test samples was regulated by a customized heating and cooling stage (HCST, Instec, Inc., Boulder, CO, USA), which was installed inside the MEC and connected to a mK1000 temperature controller and a liquid nitrogen $\left(\mathrm{LN}_{2}\right)$ pump by one electronic feedthrough and two gas feedthroughs. The diameter of the cooling area was $200 \mathrm{~mm}$. $\mathrm{LN}_{2}$ was stored in a Dewar outside the MEC for lowtemperature cooling, and this was pumped into the HCST through one gas feedthrough and pumped exhaust gas (evaporated $\mathrm{N}_{2}$ gas) was pumped out from the other. The coiled resistance wire was uniformly laid out inside the cooling stage for heating. The controllable temperature $\left(-150\right.$ to $\left.200^{\circ} \mathrm{C}\right)$ covered the temperature range of the Martian surface with good uniformity and stability $\left(\leq \pm 0.5^{\circ} \mathrm{C}\right)$. 


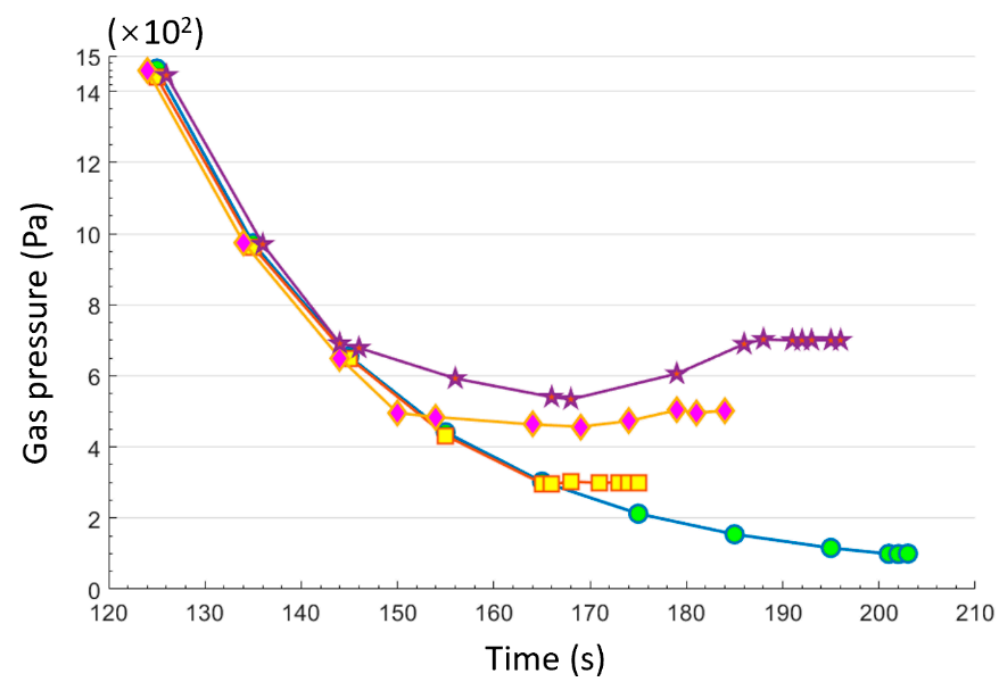

Figure 2. Typical curves of vacuum pressure with pump-down time.

A series of low-temperature experiments was performed from room temperature to $-80{ }^{\circ} \mathrm{C}$ with an interval of $-20{ }^{\circ} \mathrm{C}$. The results are shown in Figure 3A. It took approximately half an hour for every $20^{\circ} \mathrm{C}$ decrease in temperature. There were also several transient temperature oscillations at the time when the set point was first reached. The set point temperature can be well maintained for dozens of hours without human intervention.
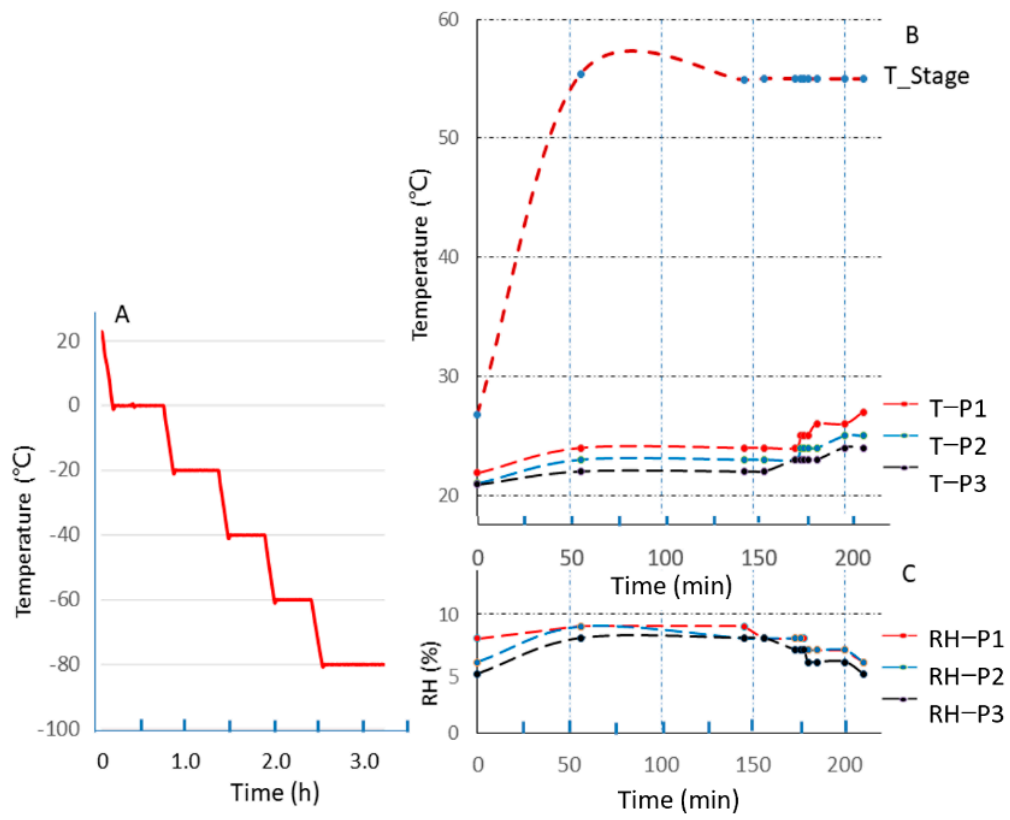

Figure 3. The heating and cooling stage (HCST) thermal and humidity cycling profile achieved in the chamber. (A) The temperature profile of HCST during cooling; (B) The temperature profiles of HCST and three-channel temperature humidity sensor above the HCST during heating; (C) The relative humidity profiles of the three-channel temperature humidity sensor above the HCST during heating.

Because of the spontaneous volatilization of water during pumping, controllable humidity is difficult to realize in a closed low-pressure chamber, which is important for the phase transition research into Martian hydrous minerals. However, it is impractical for relative humidity $(\mathrm{RH})$ control by mixing different volumes of dry and wet gas because of the condensation of water vapor on the metalware housing at various temperatures in the closed chamber. 
In this study, a beaker filled with 200 milliliters of pure water was placed inside the MEC near the HCST (distance: $100 \mathrm{~mm}$ ). A three-channel temperature humidity sensor (Xiannou, Xian, China) was used for in situ monitoring of the temperature and RH values at three different heights (Probe 1: $71.4 \mathrm{~mm}$; Probe 2: $93.0 \mathrm{~mm}$, and Probe 3: $138.3 \mathrm{~mm}$ ) immediately above the HCST. When the gas pressure of the MEC remained stable at $900 \mathrm{~Pa}$, the temperature of the HCST was set at $55{ }^{\circ} \mathrm{C}$, and it began to heat. The monitoring temperature and $\mathrm{RH}$ values with time are shown in Figure $3 \mathrm{~B}$.

It can be seen from Figure $3 \mathrm{~B}$ that an equilibrium temperature of the set point can be achieved within $50 \mathrm{~min}$. The temperatures of the three probes exhibited a very small temperature difference $\left(2-3{ }^{\circ} \mathrm{C}\right)$ and gradient $\left(1-2{ }^{\circ} \mathrm{C}\right.$ ) (uncertainty, $\left.\pm 0.5^{\circ} \mathrm{C}\right)$ due to the lower thermal conductivity at low pressure. The monitored $\mathrm{RH}$ of the three probes also showed a relatively stable value between $6 \%$ and $8 \%$ (uncertainty, $\pm 0.5 \%$ ), which means that this method can effectively obtain a stable $\mathrm{RH}$ in a narrow range during pumping. As is already known, it takes more time to reach a stable thermal equilibrium and let the heat be delivered over a long distance under low gas pressure. In this case, the HCST took about $1 \mathrm{~h}$ to stabilize at its setpoint. After $150 \mathrm{~min}$, the heat was transmitted to the three probes above the HCST, which caused a $1-2{ }^{\circ} \mathrm{C}$ increase in temperature and a decrease in relative humidity of $1-2 \%$. This is an acceptable response for the humidity to the temperature in a closed space.

\subsection{UV Radiation System}

The Martian surface is directly exposed to a high dose of UV radiation from the Sun due to the lack of an Earth-like dense atmosphere. The daily UV (UVC and UVB: 200-315 nm) fluence on the surface of present-day Mars is $361 \mathrm{~kJ} / \mathrm{m}^{2}$, which is one order of magnitude higher than that on our planet $\left(39 \mathrm{~kJ} / \mathrm{m}^{2}\right)$ [21]. Strong UV radiation has an important effect on the evolution of matter, such as atmospheric composition [22,23], surface salts [23,24], and even organic [25] or biological materials [26], not only in the upper atmosphere but also on the Martian surface.

Xe lamps have very high radiation power in the UV band and are always used as UV radiation sources for Mars-related studies. One Xe lamp (500 W, SOFN Instruments Co., Ltd., Beijing, China) was used to provide a continuum spectral output (200-1100 nm) through a quartz window for sample radiation in our laboratory.

\subsection{Sample Delivery System}

Since multiple spectral sensors were coupled on the MEC and ready for use, a sample delivery system (inset of Figure 1B) was needed to deliver samples to the right place for spectral measurement. A rotary stepping motor was hung in the middle of the chamber by a cantilever fixed on the wall of the chamber. The sample rotating platform (SRP) was an aluminum circular disk with 16 evenly distributed circular holes near the rim and was hung in parallel and near the bottom of the MEC by using a straight bar to interlink the rotary stepping motor. The HCST can be installed under the SRP for sample heating/cooling. By this design, the SRP can expediently deliver a plurality of samples to different spectral sensors under harsh conditions. During operation, the powder samples were filled in copper cups that were placed in the holes of the SRP for cooling/heating, delivery and spectral measurement. All the signal/control wires and power cords were connected to a controller outside the chamber by using electronic feedthroughs.

\section{Spectroscopic Sensors}

The MEC was equipped with four in situ spectral sensors, i.e., ASD, fiber Raman, stand-off LIBS, and emission spectrometers, which can provide complementary spectral information for mineral analysis. The ASD, fiber Raman and emission spectrometers each have their own fiber probes, which were installed inside the MEC by optical feedthroughs. All the remaining parts were installed outside the MEC. One aim of this design is to record the spectral features of some geological samples affected by the conditions inside the cham- 
ber. The other aim is to prevent the spectrometers from interference or even harm from harsh conditions inside the chamber. The safest way of doing this is to install all the major critical components outside of the chamber, except for the fiber probe. However, if the spectral sensors were designed for extraterrestrial in situ exploration, such as the fly model of the Mars payload (e.g., SuperCam, SHERLOC (The Scanning Habitable Environments with Raman \& Luminescence for Organics \& Chemicals), etc.), all parts of the payload need to be put inside the chamber for calibration and testing. The fiber probes inside the chamber were mounted on their own motorized linear translation stages (MT1-Z8, Thorlabs, Inc., Newton, NJ, USA) and traveled in an axis perpendicular to the sample surfaces for focal adjustment. The whole LIBS unit was installed outside the MEC, which used a modified Cassegrain telescope to shoot the laser, returning the plasma signal to the spectrometer through the quartz viewport of the chamber and UV-enhanced fiber. These spectral sensors can be combined to analyze one sample. To explore the unknown and complicated targets on the Mars surface, the use of hyphenated technology is a necessary and advanced strategy. LIBS gives the main information about cations, and Raman/VIS-NIR analysis gives information about the vibration mode of the anionic group [27]. Obtaining information from these hyphenated spectroscopic methods on the same set of geological samples under well-controlled environmental conditions inside the MEC establishes a better way to link the results from laboratory experiments to the Martian in situ spectral data. For all spectral sensor measurements, unless otherwise specified, at least three spectral measurements were taken per sample, to verify the sampling homogeneity and spectral reproducibility.

\subsection{ASD Probe}

In this study, one ASD spectrometer (FieldSpec 4, ASD Inc., Longmont, CO, USA) coupled with a customized vacuum Y-shaped reflectance fiber probe was used for VIS-NIR reflectance spectral measurement by using a KF40 flange to seal the probe inside the MEC under harsh conditions. This design allows one end to connect to a light source (ASD tungsten halogen lamp), while the other connects to the ASD spectrometer. The spectral band of the ASD system is $350-2500 \mathrm{~nm}$, with a spectral resolution of 3-8 nm and peak position accuracy of $0.5 \mathrm{~nm}$, which gives direct information on crystal $\mathrm{H}_{2} \mathrm{O} / \mathrm{OH}$, free $\mathrm{H}_{2} \mathrm{O}$, or adsorbed $\mathrm{H}_{2} \mathrm{O}$ on the surface of minerals by detecting overtone modes $(\sim 1.4 \mu \mathrm{m})$ and the combination H-O-H bending/stretching mode $(\sim 1.9 \mu \mathrm{m})$. The VIS-NIR reflectance spectra provide the most remarkable advances in our understanding of the water environment of the Martian surface.

The reflectance spectra of $\mathrm{NaClO}_{4} \cdot \mathrm{H}_{2} \mathrm{O}$ were collected over time at $35^{\circ} \mathrm{C}$ and $700 \mathrm{~Pa}$ with an integral time of $8.5 \mathrm{~ms}$ for every spectral collection (Figure $4 \mathrm{~A}$ ). In this study, the diameter of light sampling points on the samples was $\sim 4.5 \mathrm{~mm}$ at a distance of $10 \mathrm{~mm}$ from the fiber probe to the sample surface. The $\mathrm{H}_{2} \mathrm{O}$ absorption depths at 1.43 and $1.93 \mu \mathrm{m}$ exhibited a gradual reduction, which meant that an ongoing dehydration process was happening. Temperature and gas pressure are important factors for the dehydration process [1] and these were investigated with $\mathrm{NaClO}_{4} \cdot \mathrm{H}_{2} \mathrm{O}$ as the starting phase in this study. As shown in Figure 4B, the absorption peak area at $1.93 \mu \mathrm{m}$ represents the water content of $\mathrm{NaClO}_{4} \cdot \mathrm{XH}_{2} \mathrm{O}$. We found that at higher temperatures and lower gas pressures, a much larger amount of water was more quickly lost in this dehydration process. In Figure $4 \mathrm{~B}$, there is an unexpected increase in water absorption at the beginning of the dehydration process at $35^{\circ} \mathrm{C}$ and $300 \mathrm{~Pa}$ because of some unknown water absorption event. Besides this, the two dehydration curves of $35^{\circ} \mathrm{C}$ at 300 and 700 Pa have an almost parallel distribution along with the time. This indicates that the pressure difference of $200 \mathrm{~Pa}$ has little effect on the dehydration rate. However, there is a big difference in the dehydration rate when the temperature difference is $20^{\circ} \mathrm{C}$ (from 35 to $55^{\circ} \mathrm{C}$ ). This indicates that the variation in temperature has more of an effect on the dehydration rate than the variation in gas pressure. 

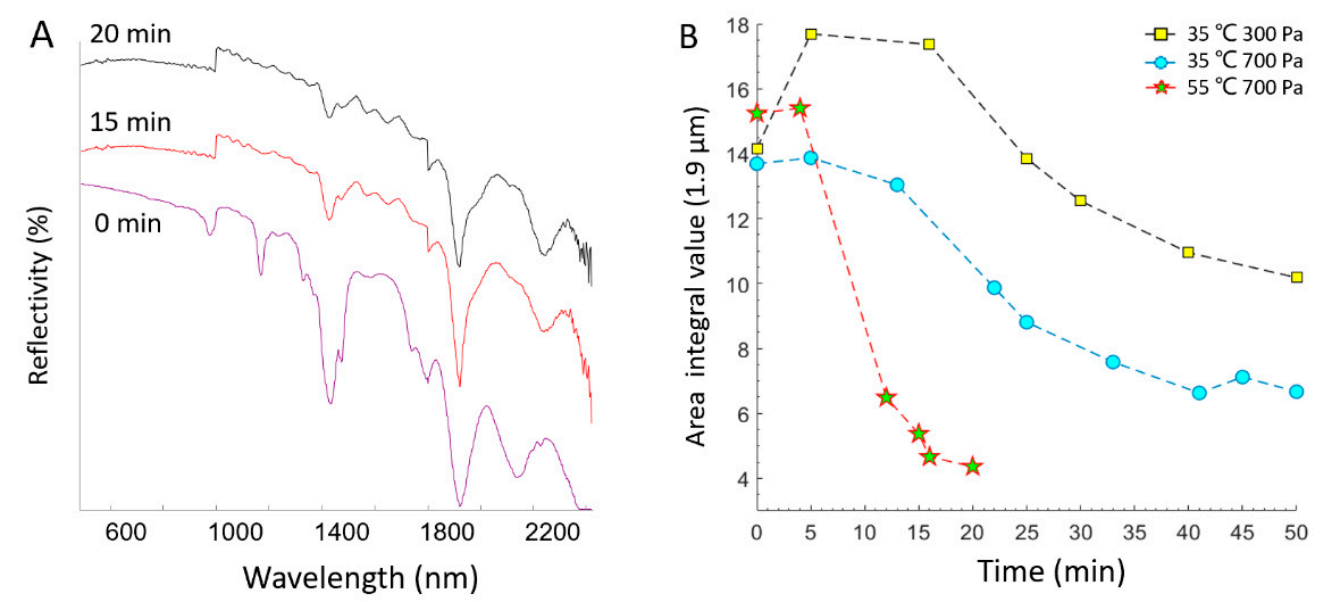

Figure 4. (A) Spectra of $\mathrm{NaClO}_{4} \cdot \mathrm{H}_{2} \mathrm{O}$ during continuous monitoring in the Mars environment chamber (MEC) at $35^{\circ} \mathrm{C}$ and $700 \mathrm{~Pa}$. (B) The decrease in the absorption band area near $1.9 \mu \mathrm{m}$ of $\mathrm{NaClO}_{4} \cdot \mathrm{H}_{2} \mathrm{O}$ as a function of time in the MEC at different temperatures $\left(35^{\circ} \mathrm{C}, 55^{\circ} \mathrm{C}\right)$ and gas pressures $(300 \mathrm{~Pa}, 700 \mathrm{~Pa})$.

\subsection{Raman Probe}

An in situ fiber Raman system was made of one customized Y-shaped Raman probe (focal length: $50 \mathrm{~mm}$, InPhotonics Inc., Norwood, MA, USA), an external diode-pumped solid $532 \mathrm{~nm}$ laser (model: 532-050-SO, $50 \mathrm{~mW}$ Crystal laser, Reno, NV, USA), a volume phase holographic spectrograph (Holospec-f/1.8i-Vis, Andor, Abingdon, Oxfordshire, UK), and an Andor ICCD spectrometer (DU416A-LDC-DD, Andor). Similar to the ASD probe, only the head end of the bifurcated fiber Raman probe was installed in the MEC by an optical feedthrough, whose excitation end was illuminated by a $532 \mathrm{~nm} \mathrm{CW}$ (Continuous Wave) laser, and the collection end was connected to the spectrometer. Both the laser and spectrometer were installed outside the MEC. The Raman probe delivered up to $\sim 10 \mathrm{~mW}$ of $532 \mathrm{~nm}$ excitation light at the sample surface $(\sim 400 \mu \mathrm{m}$ in diameter at its focus $(5 \mathrm{~mm}))$ inside the MEC. The laser power at the Raman laser focus was measured using a laser power meter (PM100D, Thorlabs). The Andor camera attached to the spectrometer records the Raman spectra from every sample (integral time, $30 \mathrm{~s}$ ) with a spectral resolution of $\sim 5 \mathrm{~cm}^{-1}$ and peak position accuracy of $\sim 0.1 \mathrm{~cm}^{-1}$ (at $520.7 \mathrm{~cm}^{-1}$ ).

Feldspar powders (30-45 $\mu \mathrm{m}$ in grain size) were poured into an aluminum cup (diameter: $40 \mathrm{~mm}$; thickness: $0.5 \mathrm{~mm}$ ), compacted, and then placed on the HCST in the MEC. The chamber was pumped and maintained at $30 \mathrm{~Pa}$. Then, the spectra of the feldspar powders were collected in situ at temperatures of $-10,-70$, and $-130^{\circ} \mathrm{C}$ when the HCST reached the set point after enough time $(10 \mathrm{~min})$ at thermal equilibrium. Low pressure does not change the mineral structure. Alternatively, no effect of gas pressure was found on the spectra of the rock/slice corresponding to our test. However, the porosity and stiffness of the powders might change during pumping, which could have an effect on the Raman spectra of the powder samples. This phenomenon was detected in our experiment, in which the intensity of the feldspar powder was reduced after pumping. From Figure 5, the spectral features of feldspar (i.e., peak position, intensity, and background) showed no changes at various low temperatures, even as low as $-130{ }^{\circ} \mathrm{C}$. This result indicated that low temperature does not affect the spectral characteristics and identification of anhydrous minerals on the Martian surface. Our previous study on some hydrated salts showed that the water peaks of $\mathrm{NaClO}_{4} \cdot \mathrm{H}_{2} \mathrm{O}$ and $\mathrm{Mg}\left(\mathrm{ClO}_{4}\right)_{2} \cdot 6 \mathrm{H}_{2} \mathrm{O}$ changed with decreasing temperature [1]. 


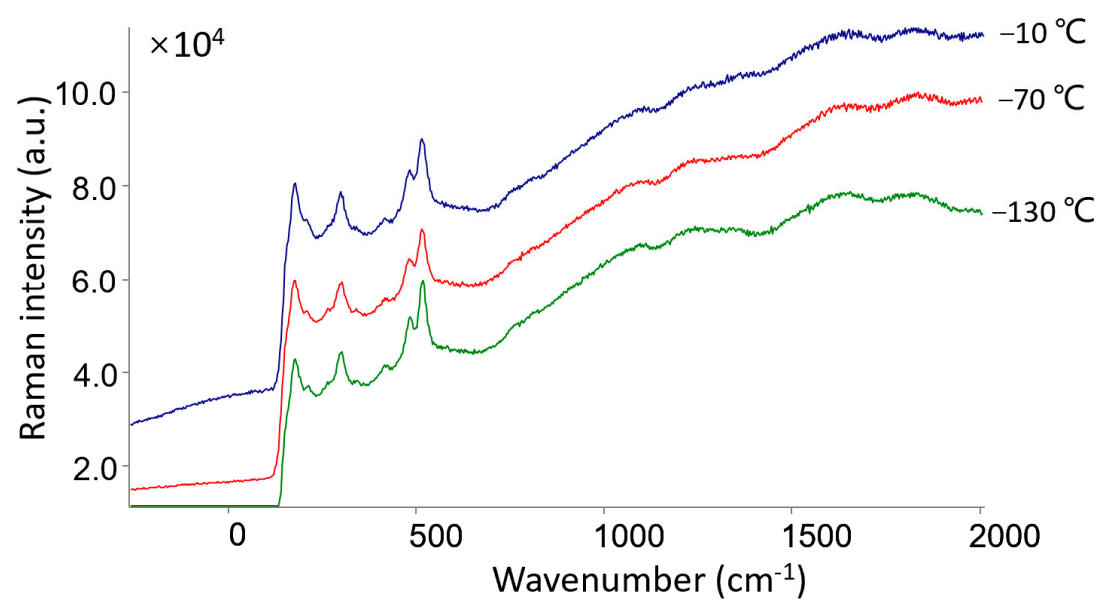

Figure 5. Raman spectra of feldspar under low temperatures $\left(-10,-70\right.$, and $\left.-130{ }^{\circ} \mathrm{C}\right)$ at $30 \mathrm{~Pa}$.

\subsection{Stand-Off LIBS}

The stand-off LIBS system was composed of one $1064 \mathrm{~nm}$ pulse laser $(200 \mathrm{~mJ}, 1-20 \mathrm{~Hz}$, pulse width: 8 ns, DW-200, Beamtech Optronics Co., Ltd.,Beijing, China), one modified Cassegrain telescope (main mirror diameter: $110 \mathrm{~mm}$; focus length: $1.0-4.0 \mathrm{~m}$ ), a homemade optical demultiplexer and three CCD (Charge Coupled Device) spectrometers (HR4000+, Ocean Optics, Dunedin, FL, USA) with different working spectral wavebands and spectral resolutions (UV: $240-340 \mathrm{~nm}$, resolution, $0.1 \mathrm{~nm}$; UV-VIS band: $340-540 \mathrm{~nm}$, resolution, $0.2 \mathrm{~nm}$; VIS-NIR band: $540-950 \mathrm{~nm}$, resolution, $0.3 \mathrm{~nm}$ ). The optical demultiplexer divides the incoming light into the above three wavelength bands to the individual spectrometers. Its optical structure is similar to the demultiplexer of ChemCam [28].

The peak position accuracy of this LIBS system is $\sim 0.18 \mathrm{~nm}$ (at $404.6 \mathrm{~nm}$ ). The telescope was used to shoot the pulse laser and collect the emission signal of excited plasma from the target, which was placed in the MEC under Martian conditions. A quartz fused silica viewport allowed this $1064 \mathrm{~nm}$ pulsed laser beam to enter the MEC, excite the target and then transmit the plasma emission spectra out to the telescope. A UV-enhanced optical fiber (core diameter: $600 \mu \mathrm{m}$ ) collected the spark of plasma from the telescope and transmitted it into an optical demultiplexer where the light was split into three bands, which were finally introduced into the three independent spectrometers. Our spectrometer $(240-950 \mathrm{~nm})$ covers the full spectral range of ChemCam (240-850 nm) and MarsCoDe (240-850 nm), with similar spectral resolutions.

A comparative study of the mineral spectral features under different environmental conditions was performed. In this experiment, gypsum powder, $\mathrm{CaSO}_{4} \cdot 2 \mathrm{H}_{2} \mathrm{O}$, was pressed into a pellet and then excited by a pulse laser at $10 \mathrm{~Hz}$ at a distance of $2.0 \mathrm{~m}$. The diameter of the sampling spot size (at focus) on the sample surface was $\sim 200 \mu \mathrm{m}$ at this distance. Each LIBS spectrum was averaged over three laser shots at every five different positions with an integral time of $1.0 \mathrm{~ms}$. The LIBS spectra of gypsum under Earth ambient conditions (Figure 6A) and simulated Martian conditions (700 $\mathrm{Pa}$ in $\mathrm{CO}_{2}$ gas) (Figure 6B) are shown in Figure 6. The photographs of plasma excited on an aluminum plate are shown in the right part of Figure 6 (Figure 6C,D). The LIBS peaks under simulated Martian conditions have lower peak intensities, especially in spectral bands that are longer than $400 \mathrm{~nm}$, have narrower spectral line widths, and have higher signal-to-noise ratios (SNRs). On the other hand, the plasma under Martian conditions (Figure 6D) was much fluffier and slightly darker than that under Earth conditions because of the lower spatial constraints at low gas pressure. The reduction in spectral line width and intensity is due to the lower collision broadening because of the low collision probability $[4,5]$ and the luminance reduction of plasma at low gas pressure. The intensity of all the LIBS lines tended to decrease with increasing laser ablation depth. Sulfur, a typical nonmetal, is relatively harder to excite; 
the emission line of sulfur was not recorded in our LIBS spectra. The emission lines of oxygen at $\sim 777.2$ and $\sim 844.6 \mathrm{~nm}$ were well recorded. However, those peaks were difficult to assign because the $\mathrm{CO}_{2}$ and $\mathrm{O}_{2}$ in the (simulated) Martian atmosphere interfered with those signals. Those peaks are not shown in Figure 6. Now, our main work is underway to build a LIBS database of calibration standards to prepare for analyzing the in situ LIBS data of MarsCoDe.

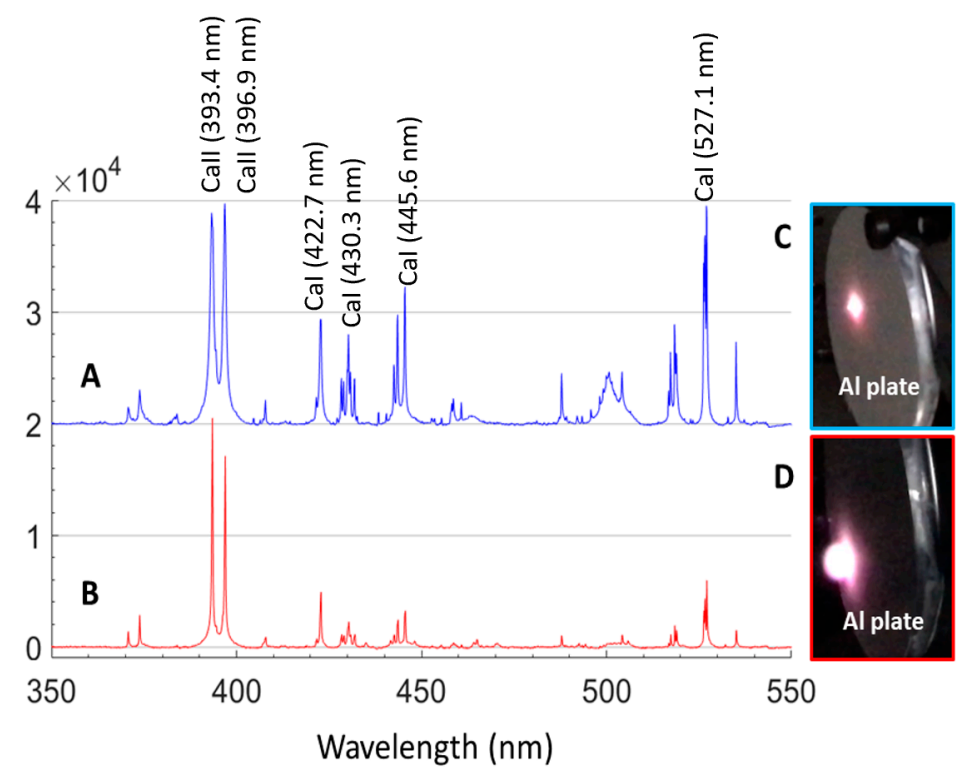

Figure 6. Laser-induced breakdown spectroscopy (LIBS) spectra of gypsum under Earth ambient conditions (A) and simulated Mars conditions (700 Pa, $\mathrm{CO}_{2}$ gas) (B); photographs of plasma excited on an aluminum plate under Earth ambient conditions (C) and simulated Mars conditions (700 Pa, $\mathrm{CO}_{2}$ gas) (D).

\subsection{Emission Spectroscopy and Dust Event Glow Discharge Simulation Unit}

Dust-event-related electrostatic discharge (ESD) has been speculated upon [29] and simulated/verified [30-32] under Mars-like conditions. Reactive species in these discharges, such $\mathrm{CO}_{2}{ }^{+}, \mathrm{H}^{+}, \mathrm{OH}^{-}$, and $\mathrm{O}$, were detected in $\mathrm{CO}_{2} \mathrm{ESD}$ reactions [32], which is a potentially important mechanism for the chemical evolution of Martian surface materials.

The reactive species can be recorded and identified by the emission spectra of $\mathrm{CO}_{2}$ glow discharge, which was also monitored during the plasma reactions to assess the capability. Here, $\mathrm{CO}_{2}$ and Earth air plasma were generated $\left(\mathrm{CO}_{2}\right.$ plasma, discharge voltage: $1 \mathrm{kV}$, inset of Figure 7) at $300 \mathrm{~Pa}$ using a low-temperature plasma power supply (CTP2000, Corona Lab, Nanjing, China). Their emission spectra in the UV band (peak position accuracy, $0.14 \mathrm{~nm}$ at 313. $2 \mathrm{~nm}$ ) are shown in Figure 7 and were mainly assigned to $\mathrm{CO}_{2}{ }^{+}$ $(288.3,289.6,313.8,325.3$, and $337.7 \mathrm{~nm})$ and $\mathrm{N}_{2}(313.5,315.8$, and $335.8 \mathrm{~nm})$ [32]. These observations provide important experimental evidence that the $\mathrm{CO}_{2}$ plasma induced by friction electrostatic discharge in Mars dust storms/devils has powerful oxidizability, which promotes the chemical evolution of surface materials. Material evolution is driven by plasma reactions due to the presence of free ions, UV radiation, free radicals, and chemically reactive neutral species. A new formation mechanism of Martian perchlorates by ESD has been proposed based on $\mathrm{CO}_{2}$ glow discharge experiments [32]. 


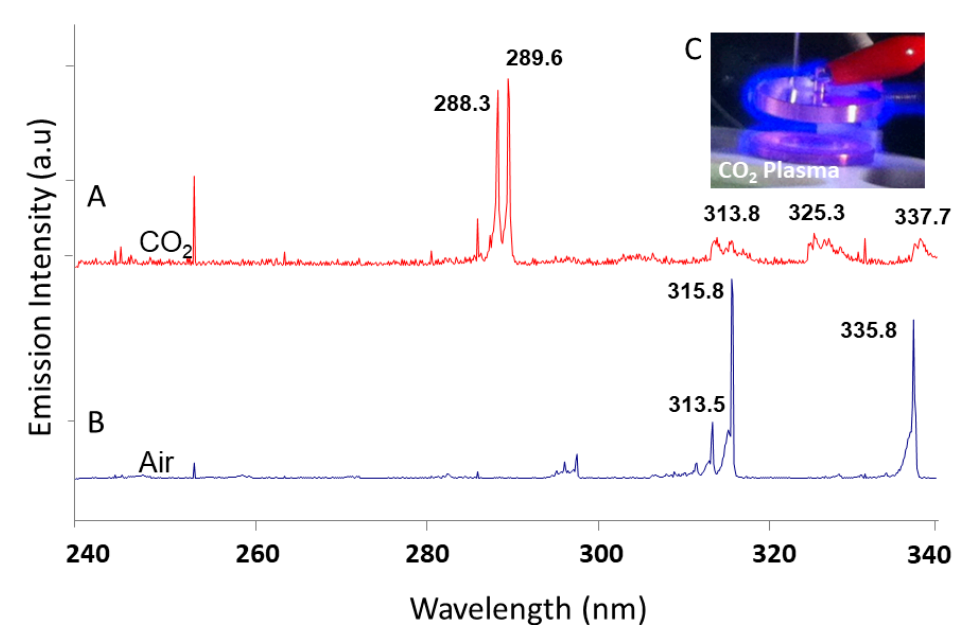

Figure 7. Emission spectra of $\mathrm{CO}_{2}(\mathbf{A})$ and air (B) under low gas pressures (300 Pa); photographs of plasma excited between two plate electrodes (C).

\section{Conclusions}

In this work, the structure, function, and performance of a newly developed MEC at Shandong University were introduced. The MEC can both regulate Mars-relative environmental parameters (gas components, gas pressure, sample temperature/humidity, and UV radiation dosage) and simultaneously/sequentially perform multiple spectral measurements such as VIS-NIR, Raman, LIBS, and plasma optical emission spectra.

Overall, three sets of experiments were undertaken to demonstrate the function and performance of MEC and the coupled spectral units. The first set was to investigate the gas pressure, temperature, and humidity functions of chamber. The results show that in the MEC it is easy to control the environmental conditions with good accuracy and repeatability. The wider parameter range and more accurate parametric control make the MEC highly adequate for mineral phase transformation and spectral analysis research work relevant to Mars. The second set of experiments investigated the working performance of the spectral sensors. The spectral characteristics (VIS-NIR, Raman, and LIBS) of some geological samples can be obtained within a few seconds under given Martian environmental conditions. Although it is challenging to record and analyze the natural rocks or heterogeneous samples on the same sampling point, the in situ multiple spectral sensors were designed to have the ability to analyze homogeneous geological samples using hyphenated and fusion spectral analysis methods. This complementary elemental and molecular information from VIS-NIR, Raman, and LIBS spectrometers under simulated harsh Martian conditions will help us better analyze and identify minerals. The third set of experiments investigated the working performance of the glow discharge unit and the emission lines of $\mathrm{CO}_{2}$ glow discharge plasma. $\mathrm{CO}_{2}$ glow discharge allows us to study chemical material evolution by Martian atmosphere plasma reactions by simulating the electrostatic discharge of Martian dust storm events. The $\mathrm{CO}_{2}$ glow discharge plasma was generated and its emission spectra were recorded and assigned. All the tested units of the MEC work well with good accuracy and repeatability.

This MEC and the multiple coupled in situ spectral sensors establish a key link between laboratory experiments and the interpretation of spectral data obtained by the Mars mission. The MEC will help us build a solid foundation for real Martian spectral data analysis and interpretation.

Author Contributions: Z.L. and Z.W. designed the entire set of experiments. Z.W., Z.L., J.Z., X.F., and C.L. conducted the chamber experiments and analyzed the data. All authors discussed and interpreted the results and contributed to the writing of the manuscript. All authors have read and agreed to the published version of the manuscript. 
Funding: The authors declare that they have no competing financial interests or conflicts of interest. This study was supported by the National Natural Science Foundation of China (U1931211, 41972322, 41573056), the Fundamental Research Funds for the Central Universities (2019ZRJC007), the Natural Science Foundation of Shandong Province (ZR2019MD008) and major research project of Shandong province (GG201809130208), and the pre-research project of Civil Aerospace Technologies No. D020102 funded by the China National Space Administration (CNSA).

Institutional Review Board Statement: Not applicable.

Informed Consent Statement: Not applicable.

Data Availability Statement: Not applicable.

Acknowledgments: We would like to thank the editors and anonymous reviewers for their constructive suggestion, which siginficantly impove the quality of this work. This is the SDU-CPS publication \#72.

Conflicts of Interest: The authors declare no conflict of interest.

\section{References}

1. Wu, Z.; Wang, A.; Ling, Z. Spectroscopic study of perchlorates and other oxygen chlorides in a Martian environmental chamber. Earth Planet. Sci. Lett. 2016, 452, 123-132. [CrossRef]

2. Jia, X.H.; Gu, W.J.; Li, Y.J.; Cheng, P.; Tang, Y.J.; Guo, L.Y.; Wang, X.M.; Tang, M.J. Phase Transitions and Hygroscopic Growth of $\mathrm{Mg}\left(\mathrm{ClO}_{4}\right)_{2}, \mathrm{NaClO} 4$, and $\mathrm{NaClO}_{4} \bullet \mathrm{H}_{2} \mathrm{O}$ : Implications for the stability of aqueous water in hyperarid environments on mars and on Earth. ACS Earth Space Chem. 2018, 2, 159-167. [CrossRef]

3. Vaniman, D.T.; Martínez, G.M.; Rampe, E.B.; Bristow, T.F.; Blake, D.F.; Yen, A.S.; Ming, D.W.; Rapin, W.; Meslin, P.-Y.; Morookian, J.M.; et al. Gypsum, bassanite, and anhydrite at Gale crater, Mars. Am. Miner. 2018, 103, 1011-1020. [CrossRef]

4. Brennetot, R.; Lacour, J.L.; Vors, E.; Rivoallan, A.; Vailhen, D.; Maurice, S. Mars analysis by laser-Induced breakdown spectroscopy (MALIS): Influence of Mars atmosphere on plasma emission and study of factors infuencing plasma emission with the use of doehlert designs. Appl. Spectrosc. 2003, 57, 744-752. [CrossRef]

5. Effenberger, J.A.J.; Scott, J.R. Effect of Atmospheric Conditions on LIBS Spectra. Sensors 2010, 10, 4907-4925. [CrossRef] [PubMed]

6. Lanza, N.L.; Wiens, R.C.; Clegg, S.M.; Ollila, A.M.; Humphries, S.D.; Newsom, H.E.; Barefield, J.E. Calibrating the ChemCam la-ser-induced breakdown spectroscopy instrument for carbonate minerals on Mars. Appl. Opt. 2010, 49, C211-C217. [CrossRef]

7. Wiens, R.; Maurice, S.; Lasue, J.; Forni, O.; Anderson, R.; Clegg, S.; Bender, S.; Blaney, D.; Barraclough, B.; Cousin, A.; et al. Pre-flight calibration and initial data processing for the ChemCam laser-induced breakdown spectroscopy instrument on the Mars Science Laboratory rover. Spectrochim. Acta Part B At. Spectrosc. 2013, 82, 1-27. [CrossRef]

8. Clegg, S.M.; Wiens, R.C.; Anderson, R.; Forni, O.; Frydenvang, J.; Lasue, J.; Cousin, A.; Payré, V.; Boucher, T.; Dyar, M.D.; et al. Recalibration of the Mars Science Laboratory ChemCam instrument with an expanded geochemical database. Spectrochim. Acta Part B At. Spectrosc. 2017, 129, 64-85. [CrossRef]

9. Manrique, J.A.; Lopez-Reyes, G.; Cousin, A.; Rull, F.; Maurice, S.; Wiens, R.C.; Madsen, M.B.; Madariaga, J.M.; Gasnault, O.; Aramendia, J.; et al. SuperCam Calibration Targets: Design and Development. Space Sci. Rev. 2020, 216, 1-27. [CrossRef]

10. Sobron, P.; Wang, A.L. A planetary environment and analysis chamber (PEACh) for coordinated Raman-LIBS-IR measure-ments under planetary surface environmental conditions. J. Raman Spectrosc. 2012, 43, 212-227. [CrossRef]

11. Hintze, P.E.; Buhler, C.R.; Schuerger, A.C.; Calle, L.M.; Calle, C.I. Alteration of five organic compounds by glow discharge plasma and UV light under simulated Mars conditions. Icarus 2010, 208, 749-757. [CrossRef]

12. Ramachandran, A.V.; Nazarious, M.I.; Mathanlal, T.; Zorzano, M.; Martín-Torres, J. Space environmental chamber for planetary studies. Sensors 2020, 20, 3996. [CrossRef] [PubMed]

13. Galletta, G.; Ferri, F.; Fanti, G.; D'Alessandro, M.; Bertoloni, G.; Pavarin, D.; Bettanini, C.; Cozza, P.; Pretto, P.; Bianchini, G.; et al. SAM, the Italian Martian Simulation Chamber. Orig. Life Evol. Biosphere 2006, 36, 625-627. [CrossRef] [PubMed]

14. Prasad, K.D.; Murty, S. Performance of a small and low-cost chamber to simulate lunar surface environment. Acta Astronaut. 2013, 89, 149-153. [CrossRef]

15. Hanna, K.L.D.; Pieter, C.M.; Patterson, W.R.; Hiroi, T.; Moriarty, D.; Wyatt, M.B.; Thompson, C. Asteroid and lunar environment chamber (alec): Simulated asteroid and lunar environments for measuring analog materials. In Proceedings of the 43rd Lunar and Planetary Science Conference, Woodlands, TX, USA, 19-23 March 2012.

16. Ortiz, Y.M.R.; Helbert, J.; Maturilli, A.; Lehmann, M. A compact planetary simulation chamber for the characterization of the bidirectional reflectance of asteroid, cometary and solar system small bodies (sssb) analogues at low-temperature en-vironments. In Proceedings of the 49th Lunar and Planetary Science Conference, Woodlands, TX, USA, 19-23 March 2018.

17. Mateo-Marti, E. Planetary Atmosphere and Surfaces Chamber (PASC): A platform to address various challenges in astro-biology. Challenges 2014, 5, 213-223. [CrossRef] 
18. Kleiman, J.; Horodetsky, S.; Issoupov, V. A planetary environmental simulator/test facility: A planetary environmental simulator/test facility. In Protection of Materials and Structures from the Space Environment; Springer: Berlin/Heidelberg, Germany, 2013; Volume 32, pp. 355-370.

19. Li, C.L.; Liu, J.J.; Geng, Y.; Cao, J.B.; Zhang, T.L.; Fang, G.Y.; Yang, J.F.; Shu, R.; Zou, Y.L.; Lin, Y.T.; et al. Scientific objectives and payload configuration of China's first Mars exploration mission. J. Deep Space Explorat. 2018, 5, 406-413.

20. Shiraishi, M.; Seo, K.; Murakami, M. Pressure and Temperature Oscillations of Working Gas in a Pulse Tube Refrigerator. In Cryocoolers 8; Metzler, J.B., Ed.; Springer: Boston, MA, USA, 1995; pp. 403-410.

21. Cockell, C.S.; Catling, D.C.; Davis, W.L.; Snook, K.; Kepner, R.L.; Lee, P.; McKay, C.P. The ultraviolet environment of Mars: Bi-ological implications past, present, and future. Icarus 2000, 146, 343-359. [CrossRef]

22. Lefèvre, F.; Bertaux, J.-L.; Clancy, R.T.; Encrenaz, T.; Fast, K.; Forget, F.; Lebonnois, S.; Montmessin, F.; Perrier, S. Heterogeneous chemistry in the atmosphere of Mars. Nat. Cell Biol. 2008, 454, 971-975. [CrossRef]

23. Civiš, S.; Knížek, A.; Rimmer, P.B.; Ferus, M.; Kubelík, P.; Zukalová, M.; Kavan, L.; Chatzitheodoridis, E. Formation of methane and (per)chlorates on Mars. ACS Earth Space Chem. 2019, 3, 221-232. [CrossRef]

24. Catling, D.C.; Claire, M.W.; Zahnle, K.J.; Quinn, R.C.; Clark, B.C.; Hecht, M.H.; Kounaves, S. Atmospheric origins of perchlorate on Mars and in the Atacama. J. Geophys. Res. Space Phys. 2010, 115. [CrossRef]

25. Rouquette, L.; Stalport, F.; Cottin, H.; Coll, P.; Szopa, C.; Saiagh, K.; Poch, O.; Khalaf, D.; Chaput, D.; Grira, K.; et al. Evolution of organic molecules under Mars-like UV radiation conditions in space and laboratory. In Proceedings of the 2017 European Planetary Science Congress, Riga, Latvia, 17-22 September 2017.

26. Kate, I.L.; Garry, J.R.C.; Peeters, Z.; Quinn, R.; Foing, B.; Ehrenfreund, P. Amino acid photostability on the Martian surface. Meteorit. Planet. Sci. 2005, 40, 1185-1193. [CrossRef]

27. Roger, C.W.; Shiv, K.S.; Justin, P.; Anupam, M.; Paul, G.L. Joint analyses by laser-induced breakdown spectroscopy (LIBS) and Raman spectroscopy at stand-off distances. Spectrochim. Acta Part A Mol. Biomol. Spectrosc. 2005, 61, 2324-2334.

28. Roger, C.W.; Sylvestre, M.; Bruce, B.; Saccoccio, M.; Barkley, W.C.; Bell, J.F.; Bender, S.; Bernardin, J.; Blaney, D.; Blank, J.; et al. The ChemCam Instrument Suite on the Mars Science Laboratory (MSL) Rover: Body Unit and Combined System Tests. Space Sci. Rev. 2012, 170, 167-227.

29. Eden, H.F.; Vonnegut, B. Electrical Breakdown Caused by Dust Motion in Low-Pressure Atmospheres: Considerations for Mars. Sci. 1973, 180, 962-963. [CrossRef] [PubMed]

30. Krauss, C.E.; Nyi, M.H.; Robertson, S. Experimental evidence for electrostatic discharging of dust near the surface of Mars. New J. Phys. 2003, 5, 70. [CrossRef]

31. Aplin, K.; Goodman, T.; Herpoldt, K.; Davis, C. Laboratory analogues of Martian electrostatic discharges. Planet. Space Sci. 2012, 69, 100-104. [CrossRef]

32. Wu, Z.; Wang, A.; Farrell, W.M.; Yan, Y.; Wang, K.; Houghton, J.; Jackson, A.W. Forming perchlorates on Mars through plasma chemistry during dust events. Earth Planet. Sci. Lett. 2018, 504, 94-105. [CrossRef] 